


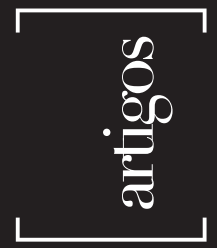


artigo

\section{A expansão das marcas e o DNA periférico}

The expansion of brands

and the peripherical DNA

\section{[ NÍZIA VILLAÇA ]}

Professora Titular da ECO/UFRJ; pesquisadora do CNPq; coordenadora do grupo ETHOS: Comunicação, Comportamento e Estratégias Corporais; co-autora do livro Em nome do corpo (Rio de Janeiro: Rocco, 1998) e autora de $A$ edição do corpo: tecnociência, artes e moda (São Paulo, Estação das Letras, 2007).

E-mail: nmvillaca@uol.com.br

[resumo] Neste artigo, busca-se analisar a dinâmica periferia/ centro como subproduto dos processos de globalização. Serão focalizados aqueles fenômenos midiáticos que, a exemplo da grife Daspu ou de documentários como Sou feia, mas tô na moda, oferecem dados para se discutir as negociações identitárias que a mídia e a indústria cultural oferecem para ressemantizar a relação centro/periferia e os processos de inclusão e exclusão.

\section{palavras-chave}

mídia; centro/periferia; corpo; moda; inclusão social.

[abstract] This paper intends to analyze the center-periphery dynamics as a production of the globalization processes. We focus on mediatic phenomena that offer data for the discussion of identity negotiations propelled by the media in the interest of renaming social processes of inclusion/ exclusion. We will take as examples the cases of the Daspu trademark and the documentary Sou feia, mas tô na moda.

[Key words] media; center/periphery; body; fashion; social inclusion. 
No primeiro número da revista $L$ 'Officiel (Alves, 2006), o editorial se referia à complexidade e à abrangência da moda e, em lugar de tendências, falava das principais conexões que estão redimensionando a moda. A principal delas seria a Nova Austeridade. A moda urbana européia se rendia ao visual sóbrio, e as novas proporções e cores começavam a seduzir brasileiros. Tal afirmativa pareceu-me em desacordo com o movimento das marcas de buscar nas ruas grande parte de sua informação/inspiração, notadamente nas culturas que Massimo Canevacci (2005) chama "eXtremas", referindo-se às mutações juvenis nos corpos das metrópoles. É nesta perspectiva que buscamos pensar a dinâmica instalada progressivamente entre a criação das marcas e o capital corporal periférico, conectando consumo e cultura e refletindo sobre alguns dos caminhos recorrentes neste universo em tempos de globalização (Villaça, 2007).

0 trajeto da moda é especialmente focado, embora as apropriações e as hibridações do centro e da periferia se desdobrem num largo espectro da produção artística e cultural: dança, música, cinema e outros. A periferia parece oferecer 0 viés diferencial perseguido, dialeticamente, pela estética globalizada.

No universo comunicacional que Muniz Sodré (2006) nomeia como "social irradiado", a disseminação das mensagens entre espaços de absorção transforma o fluxo histórico da vida social em projeções fantasiosas, numa vasta operação de próteses (telas, vídeos, máquinas inteligentes, tecnoburocratismo). Ao velho universo do encadeamento, sobrepõe-se a telerealidade, a midiatização, e afrouxam-se os laços identitários diretos de sociabilidade. De alguma forma, criam-se dois Brasis: o real e o virtual ou telerreal.

É nos interstícios desses dois Brasis, freqüentemente em violento confronto, devido à disparidade de condições materiais e de cidadania, que o sistema da moda se insere e é nesta inserção que nos parece importante observar a mão e a contramão dos contatos realizados.
A globalização traz em seu bojo uma abertura dos processos de identidade, uma grande variedade de "posições de sujeito". Nas sociedades da modernidade tardia, a concepção de identidade é mais perturbadora e provisória, caracterizada por rupturas, descontinuidades e deslocamentos, em oposição às sociedades tradicionais que perpetuavam o passado. Áreas diferentes do globo são postas em interconexão, desalojando o sistema social de suas relações espaço-temporais tradicionais, provocando novas articulações e uma concepção problemática de identidade. Quanto mais a vida social se torna mediada pelo mercado global de estilos, lugares e imagens, pelas viagens internacionais, pelas imagens da mídia e pelos sistemas de comunicação, mais as identidades parecem flutuar livremente numa espécie de supermercado cultural. As novas tecnologias informáticas, segundo Adriano Duarte Rodrigues (1990), não são instrumentos de percepção ou utensílios de produção, mas dispositivos de conexão e/ou de desconexão de formas em que o saber transforma-se num gigantesco mecanô. Uma reciclagem serializante atinge praticamente todos os domínios da cultura contemporânea, notadamente da tecnociência, da moda e das artes, com grande exuberância de processos de agenciamento das singularidades diferenciais.

É no interior desta dinâmica que o imaginário da moda progressivamente contamina de homogeneização global os lugares mais afastados e simultaneamente dota de variedade locais a linguagem globalizada.

A evolução do conceito de identidade torna-se hoje sempre mais ligada ao sistema de produção, à passagem da sociedade "industrial" à sociedade de "consumo". A partir do início da década de 1970, segundo Don Slater (2002), evidenciou-se que o sistema fordista de produção se aproximava do declínio. Custos altos e grandes riscos. As fábricas especializadas em produzir volumes enormes de mercadorias padronizadas transformam-se progressivamente em fábricas (e trabalho) destinadas a quantidades menores 
de mercadorias mais personalizadas. 0 desenvolvimento do design foi um fator de grande importância, bem como a computadorização e a robótica que baixaram o custo da reprogramação da produção para atender ao gosto sempre mais diversificado. Neste sistema pós-fordista, cresce a velocidade das informações entre os pontos de venda e os fornecedores de materiais. A administração é instantânea, o controle, maior, o prazo, menor, bem como as perdas de lucratividade com a manutenção de estoque. Os trabalhadores taylorizados, que só tomavam conta das máquinas, são substituídos pelo modelo de recursos humanos que investe na motivação, criatividade e personalidade à medida que se assume o caráter empresarial da década de 1980. Enquanto na época fordista lutava-se entre modelos competitivos de produtos, o marketing pós-fordista decompõe os mercados e 0 consumo em "estilos de vida", "nichos", "segmentos de mercado". Eles não são definidos por amplas estruturas demográficas e sociais e, sim, por significados culturais que ligam uma série de mercadorias e atividades numa imagem coerente. No pós-fordismo, as categorias de estilos de vida culturalmente constituídas substituem as categorias estruturais da sociedade como classe e gênero mais associadas ao moderno. As formas de associação e identidade fundamentadas no trabalho ou na cidadania perdem interesse, e o espírito crítico-político-ideológico abre caminho para os semiólogos e os senhores das práticas discursivas.

Com sua agenda veloz, a moda oferece uma permanente negociação de novos estilos e nichos de consumo que não se restringem ao vestuário, mas criam um clima constituído pela gestualidade e forma do corpo, tom de voz, roupas, discurso, escolhas no campo do lazer, da comida, da bebida ou do carro etc. Forma-se o perfil do indivíduo consumidor como estrato a ser considerado nos processos de subjetivação, tendo em vista o fato decisivo de que vivemos numa sociedade de consumo pós-massivo e personalizado.

Como lembra Nestor Garcia Canclini (1999), a racionalidade econômica de tipo macrossocial não é a única que modela o consumo. Refere, com propriedade, à existência de uma racionalidade sócio-políti- ca-interativa que revela a interação entre produtores e consumidores, com regras móveis, influenciando a produção, distribuição e apropriação dos bens.

A moda se espalha pela cidade, ou melhor, pelas cidades, reorganiza seus espaços, dinamizando-os como bem acentua a manchete "Rio top model" (Marra, 2006). A estética da periferia participa desta dinâmica, seja através de comunidades artesanais que cooperam com os estilistas, como, por exemplo, a Coopa-Roca (Cooperativa de Trabalho Artesanal e de Costura da Rocinha). A mídia dá notícias de um trânsito de mão dupla centro/periferia. 0 alcance do interesse despertado pela exposição "Estética da periferia: diálogos urgentes", curadoria de Gringo Cárdia, é sublinhado por Heloísa Buarque de Hollanda, estudiosa do assunto e envolvida com o projeto: "é a cultura da periferia e seu poder de resistência e criatividade artística que vem se firmando como a grande novidade que vai marcar a cultura do século XXI"[1]. Entre 13 de agosto e 16 de setembro de 2007 aconteceu uma grande exposição no Centro Cultural Banco do Brasil, o projeto "Retalhar", com a produção de designers, estilistas e artistas a partir das técnicas artesanais da Coopa-Roca (Cooperativa de Trabalho Artesanal e de Costura da Rocinha). Os cruzamentos são sempre mais numerosos e expressivos como bem revelou a dinâmica Daslu/Daspu. 0 Circo Voador, no coração da Lapa, vestiu roupa nova para receber a segunda edição da Bienal Favela Festa com a participação de oitocentos artistas ligados às favelas do Rio com desfiles, mostras de filmes, teatros etc. Mr. Catra, líder controvérsio do funk, afirma que o estilo absorve tudo, tem elementos de todas as culturas. Para a administradora do Circo, Maria Juçá, os artistas das favelas cariocas fazem uma espécie de antropofagia cultural aproveitando os refugos e devolvendo-os à sociedade em forma de arte (apud Freitas, 2007).

\section{Jogos discursivos} e o consumo da diferença

0 objetivo é pensar o imaginário contemporâneo por meio da epistemologia da comunicação e da antropologia do 
consumo. Acompanham-se as negociações realizadas entre as práticas discursivas e os eventos sociais, notadamente, observam-se os aportes virtuais e sua criação sem fronteiras, bem como a releitura e a repaginação do que é produzido pela periferia e apropriado pela indústria cultural de forma positiva, de forma negativa ou apenas politicamente correta.

É bastante complexa, segundo Normam Fairclough (2001), a reflexão sobre a mudança discursiva e a mudança social e cultural, passando pelas contradições entre as posições dos sujeitos tradicionais e as novas relações de gênero, etária, culturais de um modo geral. A mudança envolve formas de transgressão, cruzamento de fronteiras, bem como novas combinações de convenções existentes. Os processos sociocognitivos contribuirão ou não para a mudança discursiva, dependendo da natureza da prática social e vice-versa. Segundo Adriano Duarte Rodrigues (1990), a comunicação aparece hoje como questão central para a compreensão do contemporâneo, adquirindo mesmo uma posição autônoma em que diversas disciplinas sociais e humanas buscam sua validação. Para Muniz Sodré (2002), a mídia vive do discurso que faz sobre sua própria simulação das outras realidades. É a partir desta ótica que partimos para pensar a identificação de novos agentes sócio-históricos e as novas formas sócio-organizativas. Ainda segundo Muniz, aceitar a utopia de uma nova cidadania por uma pura inserção do indivíduo no mercado das teletecnologias é desconhecer a lógica capitalista nestas novas formas de sociabilização. Por sua vez, Jesús Martin-Barbero (2002), a propósito das relações entre a cultura de massa, a cultura popular e a lógica plural deste contato, fala de recuperação e deformação, mas também de réplica, cumplicidade e resistência. Há dominação, mas esta não destrói a memória de uma identidade gestada no conflito. A inflação da palavra mediação precisa gerar maiores discussões para que equívocos e simplificações não substituam os jogos discursivos de poder. A mudança deixa marcas pela dimensão textual, sua sintaxe, vocabulário técnico e não-técnico, marcador de poder. Surgem assim as novas hegemonias discursivas com maior ou menor abrangência. Uma mão dupla se instala entre a prática discursiva e a prática social, combinando a concepção foucaultiana de discurso com a ênfase de Bakhtin (Martin-Barbero, 2002).

A informática e as telecomunicações desempenham um papel importante nas transformações urbanas, acelerando ritmos, abrindo novas possibilidades de dinamização das forças produtivas, criando meios rápidos, instantâneos e abrangentes de produção e reprodução material e cultural. É nesta complexa rede que se inscrevem nossas questões a propósito da moda e da política periférica, buscando captar os sentidos da hibridação na sociedade contemporânea quando a cidade partida vai abrindo espaço para outras negociações que utilizam de forma positiva? negativa? as estratégias de visibilidade.

$\mathrm{Na}$ repaginação da periferia, o circuito da mediação fashion abre progressivamente seu campo performático geográfica e simbolicamente, pondo em cena agônica o corpo hegemônico e as corporeidades pluriformes da periferia.

É preciso conhecer as regras do jogo, as ordens dos discursos para poder estar "efetivamente" incluído nos novos tempos. Utilizo o termo "efetivamente" para contrastar o que é apontado na mídia como inclusão visual que funciona apenas como jogada de marketing pontual. Essa é a discussão quando se trata da fala periférica ou da programação periférica. É inclusão real? A escolha do casting de um figurinista caracteriza inclusão ou apropriação passageira? Nesta ótica, buscaremos a opinião de comunidades periféricas centradas na questão da moda, nos reflexos da projeção midiáticas no seu dia-a-dia, utilizando como fonte de informações entre outras o site criado no orkut intitulado "DNA periférico", ouvindo, paralelamente, especialistas sobre a dinâmica centro/periferia nas metrópoles contemporâneas e especialistas da análise do discurso.

A revista Piaui ${ }^{[2]}$, que atualmente ganha grande destaque, seria um bom exemplo do mix centro/periferia de que estamos falando a propósito da moda. Desdobram-se humoristicamente em suas páginas, num pacto entre a simplicidade local e a 
sofisticação global, matérias sobre boates \& baratos \& boemia \& semiótica \& quadrinhos \& pós-modernismo. 0 nacional e o internacional; Piauí e Nova lorque. Uma espécie de Pasquim globalizado. Hibridizações e piratarias trazem para a pauta a questão da originalidade da moda nacional em artigo de Daniela Pinheiro (2007). Enfim, a eterna questão da singularidade e da identidade.

A dinâmica da revista ilustra bem o jornalismo publicitário e globalizado. As estratégias são velozes na busca da novidade, na releitura de lugares e saberes. Se o livro impresso vai acabar, criam imediatamente a festa literária internacional de Parati em que prêmios nóbeis se confraternizam com jovens blogueiros. Verônica Stigger, escritora da nova safra, está na moda e nem sabe por quê, conforme ela mesma afirma. Os pensamentos "pops" se multiplicam entre todo tipo de recursos, plágios e óvulos mexidos. Não se sabe onde encontrar a opinião que, freqüentemente, se lança no aleatório e no contraditório. Fica sempre mais clara a importância de conhecer o último programa, a estratégia mais sutil para acompanhar as sugestivas manchetes "Cinema, Guaraná e Comunistas; de como a Coca-Cola comprou Jesus" (Piauí, junho 2007, p. 10) - (guaraná do Maranhão). Com estas poucas referências quero apenas reafirmar a importância do local inserido no contexto transnacional e na criatividade das marcas.

Se Canevacci (2005) atribui extrema importância à cultura jovem na metrópole e suas mutações, o mesmo poderiamos dizer da periferia que, aliás, tem na juventude a sua tônica. À periferia da violência e da miséria, soma-se a importância atribuída ao corpo periférico, sua linguagem, suas tiradas, sua gestualidade. A produção da periferia é capitalizada pela globalização que persegue seus signos e ritmos. Para Hermano Vianna, as próprias exposições internacionais não ficam completas sem artistas "do resto do mundo". "As diferenças são 'conectadas' por curadores que devem ter algumas das maiores milhagens aéreas do planeta" (Vianna, 2004, p. 8). Confirmando esta tendência, temos na revista de 0 Globo a manchete "Favela Chique" (Monteiro, 2007), sobre a obra batizada de Morrinho em exposição na Bienal de Veneza e agora objeto de filme sobre criativa obra de meninos favelados do morro Pereirão. Primeiro surgiu a TV Morrinho, hoje já firme no mercado; depois, o morrinho turismo que leva visitantes para o alto do Pereirão para admirar a obra; foi criada ainda a ONG Morrinho com trabalhos sociais para as crianças. E a maquete da obra foi exposta na Espanha no ano do Brasil na França na Copa da Cultura na Alemanha e, mais recentemente, na Bienal de Veneza. E tudo partiu da criatividade de meninos favelados descoberta pelos publicitários Fábio Gavião e Júlio Souto. Segundo eles, o Morrinho ainda vai render muitos frutos, e o desafio é criar produtos e sustentar a criatividade destes meninos. Tal exemplo no campo da arte se aproxima da dinâmica da Daspu em relação à produção de moda da ONG Davida ou efeitos estéticos e éticos trazidos pelas meninas funkeiras, por exemplo, no filme Sou feia, mas tô na moda.

Para Canevacci, ao longo dos fluxos móveis - plurais, fragmentárias, disjuntivas - as identidades não são mais unitárias:

ligadas a um sistema produtivo de tipo industrial, a um sistema reprodutivo de tipo familiar, a um sistema sexual de tipo monoxissista, a um sistema racial de tipo purista, a um sistema geracional de tipo biologista. $(2005$, p. 44$)$

São intersticiais, navegam no limite, são nômades. Contra os reducionismos identitários, as eliticidades são construções. A diferença como prazer de multiplicar e não como dever a ser uniformizado. A diferença é nômade, cimarrom, anômica, diaspórica. Remetendo à cultura político-comunicacional dos anos $1960 \mathrm{e}$ 1980, diz que o K recorrente na contracultura juvenil aludia ao autoritarismo e tinha entre os cachos de significados remissões críticas à política da época. Seqüencialmente, este $K$ transita do poder à potência e anuncia a catástrofe simbólica que se seguirá. Pelo contrário, o $\mathrm{X}$ aponta uma dessimbolização e se associa ao extraterrestre, ao radical, ao paranormal, ao extasy. A nova substância que irrompe nas culturas juvenis. Xé excesso, e nisto a cul- 
tura juvenil se aproxima da publicidade.

0 trânsito do $\mathrm{K}$ ao $\mathrm{X}$, segundo Canevacci, atesta (de maneira densa de estratificações de significados) a passagem da oposição juvenil do conflito político-social, próprio dos anos 1968-77-89 (que assume o K como concentrado de poder ou de potência, para desmascarar ou reivindicar, $\mathrm{K}$ como domínio do imperialismo ou como controle no próprio território), aos conflitos não-políticos, comunicacionais, metropolitanos, conferidos ao $X$, que incorpora "atravessamentos corporais, espaciais, lingüísticos caracterizados pelo irregular, pelo incontível, pelo imaterial, pelo extra como além e como anomalia. 0 extremo como eXtremo procura ultrapassar esses códigos e esses sentidos" (Canevacci, 2005, p. 44).

0 que chama a atenção no contemporâneo é que o espaço urbano, progressivamente, perde sua fisicidade geográfica, sua estabilidade, e passa a ser visivelmente elemento co-estruturante dos processos de subjetivação, contribuindo para isto toda a publicidade midiática. Para Octavio lanni (1996), a informática e as telecomunicações desempenham um papel importante nas transformações urbanas, acelerando ritmos, abrindo novas possibilidades de dinamização das forças produtivas, criando meios rápidos, instantâneos e abrangentes de produção e reprodução material e cultural.

A importância da periferia para a criação de novos nichos de consumo e agregação de valor a marcas já estabelecidas é crescente no cenário globalizado que cria simultaneamente o homogêneo e o interesse pelo heterogêneo. É sintomática a manchete da coluna de Alcino Leite Neto (2006), "África espanta o tédio do Ocidente". A crítica de arte Bérénice Geoffroy-Schneiter (apud Neto, 2006) explica, em entrevista, que o Ocidente está entediado com a uniformidade e afirma que na França há uma verdadeira histeria pela arte e pela moda feita no continente africano, não esquecendo a importância de possibilitar a emancipação das mulheres, sobretudo no que se refere à África muçulmana. Parece haver uma valorização midiática da diversidade cultural do continente sem que haja um esquecimento das guerras e doenças que ali existem.

Convém lembrar que Naomi Klein (2004) faz parêntese à sua crítica da publicidade ilusionista das marcas para lembrar a importância do barateamento do preço diante da competição que vem sendo provocada pelo tsunami China, começa a haver uma revisão do conceito de valor agregado. Desenvolvem-se modelos exclusivamente para o atacado. Profissionais dedicados farejam produtos que combinem com a grife como refrigerantes, livros e outros bens de consumo. Crescem os cursos sobre gestão de marketing e a preocupação com os nichos endereçados a segmentos sociais de nível mais baixo. A população de baixa renda ganha o interesse do mercado, não apenas como inspiração mais com o público-alvo (Rosa, 2007). As empresas enviam pesquisadores e antropólogos para acompanhar o dia-a-dia das famílias de baixa renda, observando seu comportamento e atividades de consumo. Estratégias são mudadas buscando produtos mais baratos para os segmentos de baixa renda (Brito, 2007).

Se a moda nos anos 1960 começou a sofrer a influência jovem que vinha das ruas, ela está, no momento, valorizando a estética da periferia, seja pelo seu imaginário com a utilização de grafites, fuxicos, cabelos rastafaris e outras propostas de comportamento e linguagem, muitas de caráter ambiental, visando a reativar zonas sem atrativo, como bem assinalou Zygmunt Bauman (2001) na sua modernidade líquida. Podemos observar o credenciamento espacial que a mídia promove para cima ou para baixo, num processo de promoção de eventos incessante.

A estética da periferia entre nós inclui a favela, e há um certo consenso midiático em dar voz a estes atores sociais e não apenas etiquetar sua violência. Segundo Hermano Vianna (apud Cariello, 2006), a periferia já não precisa do centro para ser avalizada, começa a adquirir voz própria e a imantar o interesse da mídia. Ivana Bentes (apud Cariello, 2006, p. E.6) a respeito do assunto, na mesma matéria jornalística, acrescenta: "não é por generosidade que o centro fala da periferia: existe uma urgência social aí. Estes sujeitos são temidos pela 
classe média". Afirma ainda Ivana que há uma necessidade de mapear e diagnosticar o que está acontecendo e aponta uma certa esquizofrenia na TV que, por um lado, faz inclusão visual e, por outro, criminaliza estes mesmos sujeitos pela violência urbana. Uma verdadeira estética do conflito se instala, e confunde-se a provisória visibilidade com a inclusão social. A morte dos meninos do tráfico que participaram do filme Falcão ou a morte de Pixote são provas óbvias que a cultura da visibilidade é bastante ambígua e curta sua temporalidade. Denílson Lopes $^{[3]}$, fala na busca de uma invisibilidade como resistência sutil ao excesso de publicidade da diferença e Vitor lório (2002) em linha semelhante fala da procura do tempo lento na informação. Para discutir a questão sob uma ótica que não seja puramente mercantilista e técnica é necessário, como afirma Sodré (2006), pesquisar os caminhos políticos das novas aberturas existenciais e comunitárias.

Pergunta-se sobre os devires da cidade entre a mídia e o efetivo desenvolvimento da periferia. Manter-se na periferia ou crescer com a mídia? - é uma pergunta que terá que ser respondida pelos diversos produtores da dinâmica centro/periferia. Líderes do cenário rap têm opiniões diferentes quanto a manter o protesto ou tornar seus produtos mais vendáveis. Mano Brown, em entrevista, afirma: "quando a mídia abriu as pernas e disse 'vem' a gente falou 'não'. Mas, se hoje chegou o momento de alguns companheiros ocuparem a mídia, eu não vou oprimir a vontade deles" (Brito, 2006, p. 6).

As negociações midiáticas entre 0 centro e a periferia que envolvem o fenômeno da moda se aceleram no mundo das imagens. Aceleram-se também as discussões sobre parcerias, explorações, piratarias e cruzamentos variados. Ferréz não abre mão da radicalidade contra a midiatização da periferia: "até que ponto um documentário que foi apresentado como 'furo jornalístico', exibido em rede nacional, nos ajuda"? (Ferréz, 2006, p. A3). Referia-se ao documentário Falcão:meninos do tráfico, de MV Bill, num enfoque que contraria a visão sempre mais inte- grada de Hermano Vianna: "o centro excluído da festa se transforma na periferia da periferia" (apud Cariello, 2006, p. E6). MV Bill diferentemente do antropólogo, está no centro do centro, quando vai ao Fantástico ou à Daslu e aceita, portanto, a Globo como intermediária ${ }^{[4]}$.

0 Brasil vai bombar com imagens brasileiras. 0 Rio de Janeiro inspirou as coleções da Osklen e da grife Do Estilista, a Cori falará do cangaceiro Lampião, 0 samba dará o tom do verão da Neon e até Glória Coelho, fã de carteirinha das cortes européias, resolveu pesquisar os antigos salões de baile de Carnaval para o seu desfile (São Paulo Fashion Week, 2007).

0 filão do chique-brega ganha importância com a personagem Bebel da novela Paraíso tropical da Rede Globo com suas roupas provenientes de larga garimpagem, segundo a figurinista Helena Gastal (Sarmento, 2007). Para Patrícia Veiga, Bebel tem humor, tem criatividade e estas são qualidades que vêm estimulando a inspiração cultural proveniente da periferia. A moda, que adora flertar com o bas-fond e ama o excesso, anda se inspirando na sensualidade que vem do batidão da rua: do funk, da perua, do calçadão (Veiga, 2007).

A produção cultural de filmes, música ou moda, sobe a favela com o que o tráfico chama "invasão do bem". Segundo o presidente da Associação de Moradores do Pavão-Pavãozinho, Marco Antônio Silva de Carvalho, o Matu, os moradores vão poder dizer depois com orgulho: "foi filmado na minha comunidade" (Ventura, 2007, p. 1). Trinta e oito pessoas das favelas do Cantagalo e Pavão-Pavãozinho são contratadas como Assistente de fotografia ou de Figurino. A menina Cristiane Santos, de vinte anos, que queria fazer educação fisica, agora quer virar figurinista. 0 repórter Mauro Ventura com a manchete "Era uma vez no morro" conta uma história que quase parece da carochinha quando bandidos, "os demonizados bárbaros", aplaudem a "invasão do bem" (Ventura, 2007, p. 1). A comunidade recebe beneficios por meio de cursos, lan houses, posto de saúde, reforma de creches etc. Esperamos que o filme "Era uma vez...", tenha um final feliz. 


\section{REFERÊNCIAS}

ALVES, Elle. Doce austeridade. L'Officiel. Ano 1, no 1, Outubro 2006.

BAUMAN, Zygmunt. Modernidade líquida. Tradução de Plínio Dentzien. Rio de Janeiro: Jorge Zahar, 2001. BRITO, Denise. Mano Brown, sem dúvidas. Folha de S. Paulo. Folhateen, 20 de novembro de 2006, p. 6.

Empresas mudam para atender baixa renda. Folha de S. Paulo. Dinheiro, 16 de julho de 2007, p. B1.

CANCLINI, Nestor Garcia. La globalización imaginada. Buenos Aires: Paidós, 1999.

CANEVACCI, Massimo. Culturas eXtremas: mutações juvenis nos corpos das metrópoles. Tradução de Alba Olmi. Rio de Janeiro: DP\&A, 2005.

CARIELLO, Rafael. Estudos analisam inclusão "na marra" de periféricos. Folha de S. Paulo, llustrada, 14 de dezembro de 2006, p. E6.

FAIRCLOUGH, Normam. Discurso e mudança social. Brasília: Universidade de Brasília, 2001.

FERRÉZ, Reginaldo. Antropo(hip-hop)logia. Folha de S. Paulo, Opinião, 5 de abril de 2006, p. A3.

FREITAS, Guilherme. Mil vezes favela. O Globo, Segundo Caderno. 19 de julho de 2007, p. 1.

IANNI, Otávio. A era do globalismo. 2 ed. Rio de Janeiro: Civilização Brasileira, 1996.

IÓRIO, Vítor. Desaceleração, interlocução e territorialidade: uma nova trajetória para a comunicação social. Tese de doutorado. Rio de Janeiro: ECO/UFR, 2002.

KLEIN, Naomi. Sem logo: a tirania das marcas em um planeta vendido. Tradução Ryta Vinagre. 4 ed. Rio de Janeiro: Record, 2004.

MARRA, Heloísa. Rio top model. 0 Globo, 3 de junho de 2006, p. 2.

MARTÍN-BARBERO, Jesús. Oficio de cartógrafo: travesías latinoamericanas de la communicación en la cultura. Chile. Fondo de Cultura Económica, 2002.

MONTEIRO, Karla. Favela Chique. O Globo. Ano 3, n ${ }^{\circ}$ 155, 15 de julho de 2007, p. 18-20

NETO, Alcino Leite. África espanta o tédio do Ocidente. Folha de S. Paulo, llustrada, 4 de agosto de 2006, p. E11.

PINHEIRO, Daniela. Coisas da Moda. Piauí, Ano 1, no 9, junho 2007, p. 34-38.

RODRIGUES, Adriano Duarte. Estratégias da comunicação e formas de sociabilidade. Lisboa: Editorial Presença, 1990.

ROSA, Bruno. O Globo, Boa Chance, 20 de maio de 2007. p. 10.

São Paulo Fashion Week - Brasil inspira coleções de verão. Folha de S. Paulo, 13 de junho de 2007, p. E 3.

SARMENTO, Claudia. O Globo, Revista da TV, 20 de maio de 2007, p. 12.

SLATER, Don. Cultura do consumo \& modernidade. Tradução de Dinah de Abreu Azevedo. São Paulo: Nobel, 2002

SODRÉ, Muniz. Antropológica do espelho: uma teoria da comunicação linear e em rede. Petrópolis: Vozes, 2002.

Sociedade, mídia \& violência. 2 ed. Porto Alegre: Sulinas: Edipucrs, 2006.

VEIGA, Patrícia. O Globo, Revista da TV, 20 de maio de 2007, p. 13.

VENTURA, Mauro. Era uma vez no morro... O Globo, Segundo Caderno. 10 de junho de 2007, p. 1.

VIANNA, Hermano. 0 exotismo nosso de cada dia. Folha de S. Paulo, Caderno Mais, 16 de maio de 2004, p. 8.

VILLAÇA, Nizia. Revista Rumos: Economia \& Desenvolvimento para os novos tempos. Consumo não faz mal a ninguém. Ano 31, nº 233, Rio de Janeiro: ABDE ed., maio-junho, 2007.

\section{FILMOGRAFIA}

Falcão. Título Original: Falcão - Meninos do Tráfico. Direção: MV Bill e Celso Athayde. Brasil, 2006. Pixote. Título Original: Quem Matou Pixote? Direção: José Joffily. Brasil,1996.

Sou feia, mas tô na moda. Título original: Sou Feia, Mas Tô na Moda.

Direção: Denise Garcia. Brasil, 2005.

\section{NOTAS}

[1]Disponivel em: <http://www.mamam.art.br/mam_exposicoes/atual.htm>

${ }^{[2]}$ A revista Piauí, editada desde 2006, é uma publicação da editora Alvinegra. Disponivel em:

$<$ http://www.revistapiaui.com.br>

${ }^{[3]}$ Denílson Lopes, professor da Escola de Comunicação da UFRJ.

${ }^{[4]}$ Disponivel em: < http://observatorio.ultimosegundo.ig.com.br/blogs.asp?id_> 